\title{
Research on Mortgage-Backed Securitization Structure
}

\author{
Yang Yue ${ }^{1, *}$, Yu Bo ${ }^{1,2}$ \\ ${ }^{1}$ Department of Mathematics, Dalian Naval Academy, Dalian, China \\ ${ }^{2}$ Department of Mathematics, Dalian University of Technology, Dalian, China
}

Email address:

49963964@qq.com (Yang Yue), yubo@dlut.edu.cn (Yu Bo)

\section{To cite this article:}

Yang Yue, Yu Bo. Research on Mortgage-Backed Securitization Structure. Science Journal of Applied Mathematics and Statistics. Vol. 4, No. 2, 2016, pp. 21-28. doi: 10.11648/j.sjams.20160402.11

\begin{abstract}
Asset securitization is an important way to improve bank asset liability structure, and can offer investors financial tools with high yields. Owing to the rapid and stable development of the financial market, the large-scale asset securitization age is on the way. To establish a complete and reasonable mortgage-backed securitization structuring model, this paper firstly introduced a method to estimate the repayment default rate based on distributional robust optimization. Then it improved a credit rating system by containing an option on the mortgage market value. Finally it proposed to use the dynamic programming model to structure the mortgage-backed securities. It is supposed to make a contribution to the financial innovation in China and put forward fresh ideals.
\end{abstract}

Keywords: Dynamic Programming, Mortgage-Backed Securitization, Distributional Robust Optimization, Default Rate, Credit Rating

\section{Introduction}

In order to alleviate the mismatch of loan for commercial banks and boost funding liquidity, the mortgage-backed securitization has significance, which can solve the shortage of bank capital, provide investors with new investment tools, and stimulate the growth of housing consumption. Accordingly, it can bloom China's financial economy and sustain the steady development of the real estate industry. However, in China this financing mode, asset securitization, is still in the stage of small experiment.

Originated from the United States in the 1960s, asset securitization has become one of the major trends in financial business. Asset securitization provides commercial banks with a new high-end financing tool to enhance its funding liquidity, to improve the capital adequacy ratio and structure, to reduce financing costs, to control risks, and to make the banking system more stable. At the same time, it can attract more investors to participate in the capital markets with higher returns.

As the first form of asset securitization, mortgage-backed securities (MBS) [1] is based on residential mortgage loan and supported by the stable installment cash flow, and regarded as a financing technique by issuing bonds. MBS were first packaged using the pass-through structure. The pass-through's essential characteristic is that investors receive a pro rata share of the cash flows that are generated by the pool of mortgages - interest, scheduled amortization and principal prepayments.

Although the operation of pass-through is very simple, one troublesome feature of the pass-through for investors is that the security's average life and level of the cash flows are uncertain, due to the right of the home buyer to prepay the mortgage loan before maturity. Depending on the interest rate environment, mortgage holders may prepay substantial portions of their mortgage in order to refinance at lower interest rates. Exercise of mortgage prepayment options has pro rata effects on all investors.

To deal with this problem and attract more investors, a more sophisticated MBS was created in the early 1980s called a collateralized mortgage obligation (CMO). The CMO repackages the cash flow according to rules for principal and interests to a series of bond classes (tranches) with different life and risk. Principal payments are funneled to investors in each tranche consecutively until the obligation is repaid. The fast-pay tranches are guaranteed to be retired first, implying that their lives will be less uncertain, although not completely fixed. Even the slow-pay tranches will have less cash-flow uncertainty than the underlying collateral. Therefore the CMO allows the issuer to target different investor groups more directly than when issuing pass-through securities. Each group can find a bond which is better customized to their particular needs.

After nearly 50 years of continuous development and innovation, mortgage securitization in the world has become 
a very mature financing technology. Many financial experts and relevant institution researchers have done a lot of researches, and they gradually formed a sound theoretical system, see Fabozzi (1995) [2]. Interests mainly in the risk measurement of asset securitization went back to Kang and Zenios (1992) [3], Schwartz and Torous (1989) [4], Jacobs (2005) [5] and so on, which studied the prepayment behavior and built the prediction model based on historical data. For the credit risk emerged in asset securization, the literature [6] provided a very simple way to estimate CMO's credit risk. On the mortgage-backed securities pricing, e.g., Bartlett (1994) [7] did the theoretical research.

However in developing countries the securitization market is still fresh. Literature about how to implement asset securitization in detail is not much. Many researchers analyzed the feasibility of the implementation of mortgage securitization in China and suggested to select $\mathrm{CMO}$ as the breakthrough. Combined with practical experience how to design CMO types and duration based on the model of mathematical optimization is a relatively new problem.

Learning from previous and related work and analyzing actual facts, this paper boldly makes use of distributional robust, option pricing, dynamic programming, nonlinear programming and other methods to model the mortgage-backed securitization structure. The model not only assesses the quality of the mortgage underlying assets in order to assign credit ratings for the corresponding bonds, but also designs the sequential principal paying CMO issuance structure. So we describe a relatively complete and reasonable mortgage-backed securitization structuring model to offer optimized solutions for implementation of the MBS in China.

\section{A Default Rate Model}

Commercial banks generally classify mortgagees according to their probability of default, loan types and so on. For a residential mortgage loan, Wang (2004) [8] put forward a credit scoring model, which selects 13 principal factors including the mortgagees' characteristics (i.e. sex, age, educational background, monthly income and occupational type), the features of the loan (i.e. the maturity, method of payment, the loan amount, loan interest rates, down-payment) and the property condition (i.e. complete department or forward delivery housing, total price) [8]. Using historical data, we can calculate the weights of these factors and get the comprehensive score for the mortgagee. Usually the probability of default is expressed as the logistic distribution function of the score [9],

$$
\operatorname{Pr} o b(\text { default })=\frac{\exp (\text { score })}{1+\exp (\text { score })} .
$$

However that just measures the default rate of a single mortgagee. Actually banks need to estimate the default risk of the loan portfolio in the pool. Since the default rates of different loans often float together with the macroeconomic or industrial characteristics, they are not completely independent. In practical application we could consider using simplified structure to reduce the number of parameters. The event of default can be expressed by a continuous variable $A_{i}, i=1, \cdots, N$. In the view of economists, $A_{i}$ is a potential variable which can decide an observable and discrete result [10]. Specially, default index variable $y_{i}$ can be expressed as

$$
\text { default }_{i} \Leftrightarrow y_{i}=1 \Leftrightarrow A_{i} \leq d_{i} .
$$

A very simple and popular example will be used to describe the mechanism of this method. We assume that $A_{i}$ obeys the normal distribution and the correlation between them stems from a common factor $Z$, that is,

$$
A_{i}=\omega_{i} Z+\sqrt{1-\omega_{i}^{2}} \varepsilon_{i}
$$

when $i \neq j, \operatorname{cov}\left(\varepsilon_{i}, \varepsilon_{j}\right)=0$ and for $\forall i, \operatorname{cov}\left(\varepsilon_{i}, Z\right)=0$, where variables $\mathrm{Z}$ and $\varepsilon_{i}$ obey the standard normal distribution and mutually independent.

For the residential mortgage loan, variable $A_{i}$ can be regarded as the market value of the mortgage house, namely the value of lender mortgage assets. So the correlations $\rho_{\mathrm{ij}}$ between these assets can be totally explained by the sensitive factor $\omega$, that is,

$$
\rho_{i j}=\frac{\operatorname{cov}\left(A_{i}, A_{j}\right)}{\sigma\left(A_{i}\right) \sigma\left(A_{j}\right)}=\omega_{i} \omega_{j}
$$

The probability of default $p_{i}=\operatorname{Pr} o b\left(A_{i} \leq d_{i}\right)=\Phi\left(d_{i}\right)$ can be decided by the threshold value $d_{i}$, where $\Phi($.$) represents$ the standard normal distribution cumulative function. Then the joint default probability is $p_{i j}=\operatorname{Prob}\left(A_{i} \leq d_{i}, A_{j} \leq d_{j}\right)=\Phi_{2}\left(d_{i}, d_{j}, \rho_{i j}\right), \quad$ where $\Phi_{2}(\cdot,, \rho)$ represents a standard bivariate normal cumulative distribution function with correlation coefficient $\rho$.

With the historical data the method of maximum likelihood estimation can be used to get the default probability $p_{i}$ and its sensitivity $\omega_{i}$ to the common factor $Z$. At first, we need a suitable distributional function to describe the default behavior, which is given by

$$
p_{i}(Z)=P\left(A_{i} \leq d_{i} \mid Z\right)=P\left(A_{i} \leq \Phi^{-1}\left(p_{i}\right) \mid Z\right)
$$

presenting the conditional default probability on the factor $Z$. According to (2), we can obtain

$$
\begin{aligned}
p_{i}(Z) & =P\left(\omega_{i} Z+\sqrt{1-\omega_{i}^{2}} \varepsilon_{i} \leq \Phi^{-1}\left(p_{i}\right) \mid Z\right) \\
& =P\left(\varepsilon_{i} \leq \frac{\Phi^{-1}\left(p_{i}\right)-\omega_{i} Z}{\sqrt{1-\omega_{i}^{2}}}\right) \\
& =\Phi\left(\frac{\Phi^{-1}\left(p_{i}\right)-\omega_{i} Z}{\sqrt{1-\omega_{i}^{2}}}\right) .
\end{aligned}
$$


Once $Z$ is certain, the randomness of (5) comes completely from $\varepsilon_{i}$. For $\varepsilon_{i}(i=1, \cdots N)$ are independent and identically distributed random variables, these conditional default probabilities are also independent. Each default index variable $y_{i}$ can be viewed as a $0-1$ random variable, and then when it equals 1 the conditional probability is $p_{i}(Z)$. If we assume that the conditional default probability for each mortgagee is $p(Z)$, the event that $N$ mortgagees from the overall $D$ mortgagees default obeys the binomial distribution and the conditional probability for default happening is $p(Z)$. Given the statistic data $N_{t}$ and $D_{t}$ in the year $t$, we can get the likelihood function for the number of default events

$$
f_{t}(\omega, p, Z)=\left(\begin{array}{c}
N_{t} \\
D_{t}
\end{array}\right) p(Z)^{D_{t}}(1-p(Z))^{N_{t}-D_{t}} .
$$

Since the factor $Z$ is a random variable, we would better considering its mathematical expectation. Let

$$
L_{t}=\int_{-\infty}^{+\infty}\left(\begin{array}{c}
N_{t} \\
D_{t}
\end{array}\right) p(Z)^{D_{t}}(1-p(Z))^{N_{t}-D_{t}} d \Phi(Z) .
$$

If there are the defaults data in the $T$ years and the default event in each year is assumed to happen dependently, we can get

$$
L=\prod_{t=1}^{T} \int_{-\infty}^{+\infty}\left(\begin{array}{c}
N_{t} \\
D_{t}
\end{array}\right) p(Z)^{D_{t}}(1-p(Z))^{N_{t}-D_{t}} d \Phi(Z)
$$

Sometimes we need to consider a more complicated portfolio with different industrial or different credit rating loans, and then we have to model the joint probability distribution for them. For simplicity this paper just focus on the residential mortgage loan, but it is still not easy to find the parameters $\omega$ and $p$ by directly maximizing $L$ defined in (7), for the integral of standard normal distribution function is so complex and the familiar first-order derivative method is infeasible. From the equality (5) we know that the relationship between $\omega, p$ and $p(Z)$. Let

$$
f(\omega, p, Z)=\prod_{t=1}^{T} f_{t}(\omega, p, Z) .
$$

Now the problem is

$$
\max _{\omega, p} E_{\Phi}(f(\omega, p, Z)) .
$$

Since in the beginning $Z$ is set as a random variable obeying the standard normal distribution, the integration in (7) is so complex. We can use the skill of discretization and treat $Z$ as an uncertain variable. Then we would find the solution easily by introducing the distributional robust optimization method [11]. Such the objective function is rewritten as

$$
\max _{\omega, p} \min _{F \in \Omega} E_{F}(f(\omega, p, Z))
$$

where $F$ is a possible cumulative distribution function of $Z$ and $\Omega$ is a set of all cumulative distribution functions satisfying that their first four order moments are consistent with the standard normal distribution random variable's. Now we can randomly generate $m$ discrete points $Z_{1}, Z_{2}, \cdots, Z_{\mathrm{m}}$, which follow the standard normal distribution and their probability are $q_{1}, q_{2}, \cdots, q_{\mathrm{m}}$ respectively. Once $\omega$ and $p$ are determined, the inner optimization problem of (9) is defined as

$$
\begin{gathered}
\min _{F \in \Omega} E_{F}(f(\omega, p, Z))=\min _{q_{1}, q_{2}, \cdots, q_{\mathrm{m}}} \sum_{i=1}^{m} f(\omega, p, Z) \cdot q_{i} \\
\text { s.t. } \sum_{i=1}^{m} q_{i}=1 \\
\sum_{i=1}^{m} q_{i} \cdot Z_{i}=0 \\
\sum_{i=1}^{m} q_{i} \cdot Z_{i}^{2}=1 \\
\sum_{i=1}^{m} q_{i} \cdot Z_{i}^{3}=0 \\
\sum_{i=1}^{m} q_{i} \cdot Z_{i}^{4}=3 \\
q_{i} \geq 0, i=1,2, \cdots, m .
\end{gathered}
$$

The $m$ discrete points $Z_{1}, Z_{2}, \cdots, Z_{\mathrm{m}}$ are known, so (10) is a tractable linear programming problem. The dual problem of (10) is

$$
\begin{gathered}
\max _{\theta, \alpha_{1}, \alpha_{2}, \alpha_{3}, \alpha_{4}} \theta+\alpha_{2}+3 \alpha_{4} \\
\text { s.t. } \quad \theta+Z_{i} \alpha_{1}+Z_{i}{ }^{2} \alpha_{2}+Z_{i}^{3} \alpha_{3}+Z_{i}^{4} \alpha_{4} \leq f\left(\omega, p, Z_{i}\right), \\
i=1,2, \cdots, m .
\end{gathered}
$$

When conditions meet the strong duality theorem [12], the optimization problem (9) can be written as the following program,

$$
\begin{gathered}
\max _{\omega \in[0,1], p \in[0,1]} \max _{\theta, \alpha_{1}, \alpha_{2}, \alpha_{3}, \alpha_{4}} \theta+\alpha_{2}+3 \alpha_{4} \\
\text { s.t. } \quad \theta+Z_{i} \alpha_{1}+Z_{i}^{2} \alpha_{2}+Z_{i}^{3} \alpha_{3}+Z_{i}^{4} \alpha_{4} \leq f\left(\omega, p, Z_{i}\right), \\
i=1,2, \cdots, m .
\end{gathered}
$$




\section{Credit Ratings}

The prepayment risk refers the home buyer to prepay the mortgage loan before maturity, leading to the reduction in interest and risk in bond yields. The 100\% PSA (Public Securities Association) industry-standard benchmark is too simple and does not match with the actual. Kang and Zenios (1992) [3] proposed a prepayment model based on publicly available data, which contained four variables: seasonal variations, refinancing incentive, seasoning effect and burnout effect. That model showed a better applicability. The prepayment behavior is very common in China, mainly due to interest rates, the level of income, the real estate market prices, and the concept of consumption and so on. The optimal structure presented in this paper can be applied to all specific prepayment models, so we no longer describe the prepayment model in detail.

Let's take a mortgage for example, analyze the yearly cash flow with the assumption of prepayment. Consider a personal housing mortgage loan $Q_{0}$ with a maturity $T$ and a fixed yearly interest rate $r$, assuming the same total payment (interest + scheduled amortization) each year. The outstanding principal at the end of year $t$ is $Q_{t}(t=1, \ldots, T)$. The rate of mortgage prepayments in year $t$ is $q_{t}$. In this year the interest payment $I_{t}=r \cdot Q_{t-1}$, the amortization payment $A_{t}=\frac{I_{t}}{(1+r)^{T-t+1}-1}$, there is a prepayment $R_{t}=q_{t}\left(Q_{t-1}-A_{t}\right)$ collected at the end of year $t$. Thus the principal pay down is $P_{t}=R_{t}+A_{t}$ in year $t$. The outstanding principal at the end of year $t$ is $Q_{t}=Q_{t-1}-P_{t}$.

Each year cash flows from the mortgage consist of the interest and principal (including the prepayment). In this paper CMO repackages the principal flows $\left(P_{1}, \ldots, P_{T^{1}}\right)$, $\left(P_{T^{1}+1}, \ldots, P_{T^{2}}\right), \ldots,\left(P_{\ldots}, \ldots, P_{T}\right)$ constructing a series of bonds with different characteristics. Let us refer the candidate tranche $\left(P_{j}, \ldots, P_{t}\right)$ as $(j, t)$, starting amortizing at the beginning of year $\mathrm{j}$ and ends at the end of year $\mathrm{t}$ with the principal payment $P_{k}, k=j, \ldots, t$.

The convention in mortgage markets is to price bonds and measure risks with respect to their weighted average life (WAL), which is much like duration, i.e.,

$$
W A L_{j t}=\frac{\sum_{k=j}^{t} k \cdot P_{k}}{\sum_{k=j}^{t} P_{k}}
$$

Here we can use the credit risk measurement method for commercial banks' mortgage based on the Merton (1974) [13] model for reference. As a creditor, when the bank issued a personal housing mortgage loan, it owned a coupon bonds in long position with the par value $Q_{0}$ and a maturity $T$ and a portfolio constituted by several short put options with exercise prices $Q_{t}$ (the outstanding principal at the end of year $t$ ). $F_{t}$ is the put option's value, then the actual value of mortgage balance in year $t$ is

$$
B_{t}=Q_{t} e^{-r_{t} \cdot t}-F_{t}
$$

Make assumptions:

(1) There is no friction in the real estate market and no transaction costs.

(2)The value of housing $V_{t}$ follows a geometric Brownian motion: $\frac{d V_{t}}{V_{t}}=r_{t} d t+\sigma d W_{t}$, in which $W_{t}$ is a Winner process. Let $V_{t}^{\prime}$ be the value of mortgage housing at the end of year $t$. It's easy to prove that

$$
\ln V_{t}^{\prime} \sim N\left(\ln V_{t}+\left(r_{t}-\frac{\sigma^{2}}{2}\right), \sigma^{2}\right)
$$

(3) During the life of the option (assumed one year), the risk-free rate $r_{t}$ and the volatility of housing values $\sigma$ remain unchanged.

(4) The put option is a European option.

(5) Real estate transactions can be carried out continuously. When $V_{t}^{\prime}<Q_{t}$, the mortgagee may choose to default. For the put option $F_{t}=\max \left(0, Q_{t}-V_{t}\right)$. According to the Black-Sholes [14] pricing formula, we have

$$
F_{t}=Q_{t} e^{-r_{t}} \Phi\left(-d_{2}\right)-V_{t} \Phi\left(-d_{1}\right),
$$

where $d_{1}=\frac{\ln \left(\frac{V_{t}}{Q_{t}}\right)+\left(r_{t}+\frac{\sigma^{2}}{2}\right)}{\sigma}, d_{2}=d_{1}-\sigma, t=1,2, \ldots, T$.

The outstanding principal $Q_{t}$ at the end of year $t$ is related to reimbursement means and is the function of loan interest rates, down payment ratio (not considered in this paper), maturity and prepayment rates. Bring (14) into (13), we obtain

$$
B_{t}=Q_{t} e^{-r_{t}}-Q_{t} e^{-r_{t}} \Phi\left(-d_{2}\right)\left[1-\frac{V_{t} \Phi\left(-d_{1}\right)}{Q_{t} e^{-r_{t}} \Phi\left(-d_{2}\right)}\right] .
$$

It can be proved that the probability of default is $P D=\operatorname{Prob}\left(V_{t}^{\prime}<Q_{t}\right)=\Phi\left(-d_{2}\right)$. When default occurs with the assumption that bankruptcy cost is not considered, the expected recovery rate is

$$
\begin{gathered}
P R=E\left(\frac{V_{t}^{\prime}}{Q_{t}} \mid V_{t}^{\prime}<Q_{t}\right)=\frac{1}{Q_{t}} E\left(V_{t}^{\prime} \mid V_{t}^{\prime}<Q_{t}\right) . \\
E\left(V_{t}^{\prime} \mid V_{t}^{\prime}<Q_{t}\right)=\exp \left(r_{t}^{*}+\frac{\sigma^{* 2}}{2}\right) \frac{\Phi\left(\frac{\ln Q_{t}-r_{t}^{*}}{\sigma^{*}}-\sigma^{*}\right)}{\Phi\left(\frac{\ln Q_{t}-r_{t}^{*}}{\sigma^{*}}\right)},
\end{gathered}
$$


where $r_{t}^{*}=\ln V_{t}+\left(r_{t}-\frac{\sigma^{2}}{2}\right), \sigma^{*}=\sigma$. From (16) we have

$$
\begin{gathered}
E\left(\frac{V_{t}^{\prime}}{Q_{t}} \mid V_{t}^{\prime}<Q_{t}\right)=\exp \left(\ln V_{t}+r_{t}\right) \frac{\left(-\frac{\ln \left(\frac{V_{t}}{Q_{t}}\right)+\left(r_{t}+\frac{\sigma^{2}}{2}\right)}{\sigma}\right)}{\Phi\left(-\frac{\ln \left(\frac{V_{t}}{Q_{t}}\right)+\left(r_{t}-\frac{\sigma^{2}}{2}\right)}{\sigma}\right)} \\
=V_{t} e^{r_{t}} \frac{\Phi\left(-d_{1}\right)}{\Phi\left(-d_{2}\right)} .
\end{gathered}
$$

So, $P R=E\left(\frac{V_{t}^{\prime}}{Q_{t}} \mid V_{t}^{\prime}<Q_{t}\right)=\frac{V_{t}}{Q_{t} e^{-r_{t}}} \frac{\Phi\left(-d_{1}\right)}{\Phi\left(-d_{2}\right)}$. On the basis of IRB (Internal Ratings-Based) approach, (15) has the following explanation,

$$
\frac{B_{t}}{Q_{t} e^{-r_{t}}}=1-P D \times L G D
$$

where the loss given default $L G D=1-P R, P D \times L G D$ indicates the expected loss rate. Default rates, recovery rates and expected loss rates are the core indexes to judge the quality of the mortgage assets pool.

The credit rating for asset securitization is different from common stocks, which mainly think about the recoverable equities investors can get in the asset securitization transactions. It's based not only on house buyers' credit situation, but also mostly on the configuration structure of the asset pool and investors' recoverable equities. Let $B_{t}$ be the value of mortgage balance in year $t, Q_{o}$ be the total value of the asset pool, $p$ be the expected default rate, then for tranche $(j, t)$ the credit rating has to satisfy the formula

$$
B_{t} \geq Q_{0} \cdot p \cdot W A L_{j t} \cdot L \text {. }
$$

In order to achieve a high quality rating, tranches should be able to sustain higher than expected default rates without compromising payments to the tranche holders. For this reason, credit ratings are assigned based on how much money is "behind" the current tranche. That is, how much outstanding principal $B_{t}$ is left after at the end of year $t$ when the current tranche is retired, as a percentage of the total amount of principal. This is called the "buffer". Early tranches receive higher credit ratings since they have greater buffers, which mean that the CMO would have to experience very large default rates before their payments would be compromised. In (18) L refers to as the "loss multiple" to describe the level of withstand risks.

$$
L=\max \left\{L \in\{0,1.5,2,3,4,5,6\} \mid B_{t} \geq Q_{0} \cdot p \cdot W A L_{j t} \cdot L\right\}
$$

According to the loss multiples and credit rating table (Table 1) as follows, we can assess the credit rating for this tranche.

Table 1. Credit Rating.

\begin{tabular}{llllllll}
\hline Credit Rating & AAA & AA & A & BBB & BB & B & CCC \\
\hline Loss Multiple & 6 & 5 & 4 & 3 & 2 & 1.5 & 0 \\
\hline
\end{tabular}

Pricing is also affected by bond yields, which is usually determined by the benchmark interest rate and credit spreads (risk premium). Benchmark interest rate is universally referred in the financial markets and in many countries it usually equals the current treasury rate. Due to the existence of credit risk, market risk, interest rate risk and banks' operation risk, mortgage-backed securities investors face high investment risk. So they require higher returns than a risk-free bond (current treasury) with the approximate duration. The spread is called risk premium, which is proportional with the risk.

The reader can get more current figures from professional rating agencies with high public recognitions. Spreads on corporate bonds with similar credit ratings would provide reasonable figures. These rates appear in the next table 2 is an example.

Table 2. Credit Spread Rate.

\begin{tabular}{lllllllll}
\hline \multirow{2}{*}{ Period(t) } & $\begin{array}{l}\text { Risk-Free } \\
\text { Spot }\end{array}$ & Credit Spread in Basis Points \\
\cline { 2 - 9 } & AAA & AA & A & BBB & BB & B & CCC \\
\hline 1 & $2.18 \%$ & 85 & 100 & 115 & 130 & 165 & 220 & 345 \\
2 & $2.54 \%$ & 90 & 105 & 125 & 140 & 190 & 275 & 425 \\
3 & $2.80 \%$ & 95 & 110 & 135 & 150 & 210 & 335 & 500 \\
$\ldots$ & $\ldots$ & $\ldots$ & $\ldots$ & $\ldots$ & $\ldots$ & $\ldots$ & $\ldots$ & $\ldots$ \\
\hline
\end{tabular}

Note: The unit of spread is a basis point, i.e. $1 \%$ of $1 / 100$.

\section{Dynamic Programming Model to Structure CMO}

In this paper we will take the perspective of an issuer of sequential CMOs [15]. Issuers make money by issuing CMOs because they can pay interest on the tranches that is lower than the interest payments being made by mortgage holders in the pool. The objective is to minimize the present value of total payment (interest + scheduled amortization) to bondholders

$$
v(k, t)=\min \left\{\begin{array}{l}
\text { present value of total payments to bondholders } \\
\text { from year } 1 \text { to year } \mathrm{t}, \text { when the CMO has } \mathrm{k} \\
\text { tranches up to year } \mathrm{t} .
\end{array}\right\}
$$

In this section, we present a dynamic programming recursion for solving these problems. How many tranches should be issued? Which sizes? Which coupon rates?

Constructing a dynamic programming model, we have to take five steps below.

Step1 Objects are the sizes of each tranche. The stages will be the number $\mathrm{k}$ indexing the $\mathrm{kth}$ tranche, $k=1,2, \ldots, K$.

Step2 The states of the dynamic program will be the years 
$t$ indicating that the kth tranche is expired in year $t$, $t=1,2, \ldots, T$.

Step3 Making decisions when the kth tranche starts receiving principals. All possible decisions constitute the decision set $S=\{k, k+1, \cdots, t-1\}$. If choosing the decision $j \in S$, the tranche $(j, t)$ is determined.

Step4 Determining the cost function, and here it is the discounted value of all cash flows the kth tranche received.

For the tranche $(j, t)$, given principal flows $\left(P_{j}, \cdots, P_{t}\right)$, $B_{t}$ and $W A L_{j t}$ can be calculated. Thus from the formula (19) we can get $L$ and credit rating for the kth tranche in accordance with Table 1. According to the Table 2 we can find the corresponding risk-free interest rates and credit spreads,

and by adding them we get the kth tranche's coupon rate $c_{j t}$.

Define $T_{j, t}$ to be the present value of the payments on a tranche $(j, t)$. Armed with the certain coupon rate $c_{j t}$ and a full curve of spot rates $r_{t}, T_{j, t}$ is computed as follows.

Set $C_{k}$ to be the cash flow generated during the period $k$. When the principal is not paid, that is, $k<j, C_{k}=c_{j t} \cdot P_{j t}$, there $P_{j t}=\sum_{k=j}^{t} P_{k}$, in other words $P_{j t}$ is the total principal of tranche $(j, t)$. During these periods $(k<j)$ only interest is received.

When $k \in[j, t]$, the tranche bondholders start receiving principal payments $C_{k}=c_{j t} \cdot P_{j t}(k)+P_{k}, \quad$ where $P_{j t}(k)=\sum_{n=k+1}^{t} P_{n}$ and $P_{j t}(t)=0$.

Then the present value $T_{j, t}=\sum_{k=1}^{t} C_{k} \cdot d f(k)$, where the discounted operators $d f(k)=\prod_{i=1}^{k} \frac{1}{\left(1+r_{i}\right)}, \quad r_{i}$ is the discount rate in year $i$.

Step5 Establish the state transition equation. For this model, if selecting decision $j$ in the stage $k$, by constructing a reverse dynamic programming the state of the previous stage $k-1$ goes directly to $j-1$, which is decided by the CMO's sequential principal paying structure. As a result, the state transition equation is $T_{k}(j)=j-1$.

The optimal objective value, i.e., the basic equation of dynamic programming for this problem is given by

$$
v(k, t)=\min _{j=k, \ldots, t}\left\{v(k-1, j-1)+T_{j, t}\right\}
$$

If considering issuing $K$ tranches and the maturity is until the year $T$, the objective function of dynamic programming model is $v(K, T)$.

For the bonds issuer, its capital flows situation can be summarized as "two into " and "three out" [16]. The "two into" includes the present value $A$ of cash flows generated by the underlying assets in the pool and income $B$ from the bonds issuances. The "three out" includes the purchase cost $C$ of the underlying asset pool, the present value $D$ of principal and interest payments to investors and all kinds of securities issuance costs $E$.

Now we assume that the underlying asset pool is comprised by $n$ bills of individual mortgage loans, among which the value of the ith loan bill is $Q_{i}$ with yearly loan rate $R_{i}$ and maturity $T_{i}$. According to the construction principle for asset pool, that is, facilitate operation, the same standard and risk diversification, we assume that,

1) The loan bills with different credit ratings, loan amounts, maturities constitute the mortgages set by their weights. So we have the average loan rate $r^{\prime}=\sum_{i=1}^{n} \omega_{i} R_{i}$, the average maturity $T^{\prime}=\sum_{i=1}^{n} \omega_{i} T_{i}$, in which the weights $\omega_{i}=\frac{Q_{i}}{Q^{\prime}}$ and $Q^{\prime}$ is the total loan amount, i.e., $Q^{\prime}=\sum_{i=1}^{n} Q_{i}$. In order to easily forecast the cash flows generated by the underlying assets and estimate their risks, it's general to select loans with high homogeneity to form the pool of assets. To be specific, these mortgage loans have close loan rates, maturities and approaching expiration dates.

2) Interests are paid once a year.

If the expected prepayment rate is certain in accordance with the calculation step in Section 2, we can figure out per the principal and interest cash flows received in each period for each loan, i.e., $S_{i t}=P_{i t}+I_{i t}$, where the discount operator $d f(k)$ is defined as above. We have the expression

$$
A=\sum_{i=1}^{n} \sum_{t=1}^{T_{i}} S_{i t} d f(t)
$$

It's hardly possible to analyze the repayment rate for each loan in the pool. So we use the weighted average loan rates and the weighted average maturity to predict the prepayment rate $q_{t}^{\prime}\left(t=1,2, \ldots, T^{\prime}\right)$ for the entire mortgage, and then calculate the cash flows $S_{t}$ of the portfolio loan pool in each period, i.e.,

$$
S_{t}=\frac{\left(1+r^{\prime}\right)\left[\left(1+r^{\prime}\right)^{T^{\prime}-t}\left(q_{t}^{\prime}+r^{\prime}\right)-q_{t}^{\prime}\right] Q_{t-1}^{\prime}}{\left(1+r^{\prime}\right)^{T^{\prime}-t+1}-1} .
$$

The bond sponsor (e.g. a commercial bank) wants to shift risks and improve the capital structure, and he generally sells the mortgage loan at a discount because the borrowers' credit may be poor, lack of abilities to repay, or sometimes the loan even might be a higher default risk subprime mortgage, which is likely to become the NPL (no-performing loan). So the discount rate $k_{i}$ is positively correlated to the loan risks. We 
assume that

$$
k_{i}=f\left(x_{1}, x_{2}, \ldots, x_{s}\right)
$$

where these quantitative parameters $x_{i}(i=1, \cdots, s)$ index the borrower's historical credit status, present debt conditions, the loan amount and so on. So we obtain

$$
C=\sum_{i=1}^{n}\left(1-k_{i}\right) Q_{i}
$$

In accordance with the calculation steps given earlier, the total present value of $\mathrm{CMO}$ bonds with $K$ tranches and the allotted time $T$ needed to pay investors is $D=v(K, T)$. During the process of calculation we ensure the coupon rate $c_{k}$ for each tranche with the par value $P(k)$ (the total principals received) and maturity $T^{k}$. Thus we know the allotted time $T=\sum_{k=1}^{K} T^{k}, k=1, \ldots, K, \quad$ and the sum of insurance prices for all different tranches is

$$
B=\sum_{k=1}^{K}\left\{\frac{P(k)}{(1+\tilde{r})^{T^{k}}}+\sum_{t=1}^{T^{k}} \frac{P(k) c_{k}}{(1+\tilde{r})^{t}}\right\}
$$

where $\widetilde{r}$ is the discount rate in the period of issuance.

Securities issuance costs $E$ mainly include: the fees of asset restructure, charges paid to securities underwriters, such as: printing costs for securities and related certificates, distribution fees, advertising fees, arrangement fees of selling networks and subscription, etc. And it also includes fees paid to commission managers and lawyers, collateral costs and charges paid to a third-party credit rating agency and so on.

Let $E$ be the net cash inflow for bonds issuer. From above we have

$$
N=A+B-C-D-E .
$$

There some constraints will be considered as follow

1) Selection constraints for investors.

Investors choose the CMO securities if and only if their interest income (risk premium) is much higher than the risk-free income (e.g. current treasury, and the risk free spot is $R$ ) at the same time with the same capital costs, that is,

$$
\sum_{i=1}^{n} Q_{i}\left[(1+R)^{T_{i}}-1\right]<\sum_{k=1}^{K} P(k)\left[\left(1+c_{k}\right)^{T^{k}}-1\right]
$$

Either we can use the average interest rates to calculate the average interest income of the loan portfolio pool, i.e.,

$$
Q^{\prime}\left[\left(1+r^{\prime}\right)^{T^{\prime}}-1\right]<\sum_{k=1}^{K} P(k)\left[\left(1+c_{k}\right)^{T^{k}}-1\right]
$$

2) Liquidity constraints.

In order to reduce liquidity risk, the maturity of issued securities cannot exceed the average maturity of those loans, namely,

$$
T=\sum_{k=1}^{K} T^{k} \leq \sum_{i=1}^{n} \omega_{i} T_{i}=T^{\prime}
$$

3) Issuance cost constraints.

Since the securities' credit was enhanced by the third-party agency to lower the risks, their issuance costs will be rather low. Securities issuers who want to earn returns must make sure that the coupon rate of each tranches is less than the weighted average loan rates, i.e.

$$
c_{k}<\sum_{i=1}^{n} \omega_{i} R_{i}, \quad k=1, \cdots, K .
$$

From the issuer's point of view, they hope to avoid risks while maximize the benefits. Thus the optimal model is given by

$$
\begin{gathered}
\max _{K, T} \sum_{t=1}^{T^{\prime}} S_{t} d f(t)+\sum_{k=1}^{K}\left\{\frac{P(k)}{(1+\tilde{r})^{T^{k}}}+\sum_{t=1}^{T^{k}} \frac{P(k) c_{k}}{(1+\tilde{r})^{t}}\right\}-\sum_{i=1}^{n}\left(1-k_{i}\right) Q_{i} \\
-\min _{j=K, \cdots, T}\left\{v(K-1, j-1)+T_{j, T}\right\}-E \\
\text { S.t. } \quad Q^{\prime}\left[\left(1+r^{\prime}\right)^{T^{\prime}}-1\right]<\sum_{k=1}^{K} P(k)\left[\left(1+c_{k}\right)^{T^{k}}-1\right] \\
T=\sum_{k=1}^{K} T^{k} \leq \sum_{i=1}^{n} \omega_{i} T_{i}=T^{\prime} \\
c_{k}<\sum_{i=1}^{n} \omega_{i} R_{i}, \quad k=1, \cdots, K
\end{gathered}
$$

$Q_{i}>0, P(k)>0, c_{k}>0, K<T$ and they are all positive integers, $i=1, \cdots, n, k=1, \cdots, K$.

At first this nonlinear cash flow model can quantitatively determine whether to issue these securities. Only if $N>0$ issuance is profitable. Then the model can solve the question how to issue, namely how many tranches should be issued and how to design their maturities.

\section{Conclusion}

When elaborating on the CMO securities issuance structure, we stand from the perspective of issuers to structure the cash flow model. By using simulated data to do some numerical experiments we found that the $\mathrm{CMO}$ structure with three or four tranches is better. This result is consistent with the actual situation, so to some extent this mode has practical significance. However, MBS in China has just started, e.g. the first MBS product "Jianyuan 2005-1" will not finish its first cycle until November 26, 2037. Therefore we cannot collect real data to validate the model, and the constraints considered there are also so limited mainly due to the lack of practical experience. Through studying this paper we want to put forward such an idea to model the issuance structure of sequential principal paying CMO. The validity of this model is hoped to be verified and improved in the near future. 


\section{References}

[1] W. D. Chen, A. Y. Li, X. X. Liao. The Theory and Practice of Asset Securitization. Beijing, China: Renmin University Press, 2004.

[2] F. J. Fabozzi. The Handbook of Mortgage-Backed Securities. $5^{\text {th }}$ ed. New York, US: McGraw-Hill, 2001.

[3] P. Kang, S. A. Zenios. "Complete Prepayment Models for Mortgage-Backed Securities". Management Science, Focused Issue on Finance Modeling, 1985, vol. 3, pp. 385-408.

[4] R. Schwartz, W. N. Torous. "Prepayment and the variation of mortgage-backed securities". Journal of Finance, 1989, vol. 6, pp. 375-392.

[5] J. Jacobs, R. Koning, E. Sterken. "Modelling Prepayment Risk". Technical report, University of Groningen, 2005.

[6] K. Rajaratnam. A Simplified Approach to Modeling the Credit Risk of CMO. arXiv: 0903.1643, 2009, 3. http://www.researchgate.net/publication/24163603.

[7] W. Bartlett. The Valuation of Mortgage-Backed Securities. New York, US: Irwin Professional Publishing, 1994.

[8] F. L. Wang. "Empirical research on default risk factors of residential mortgage loan". Zhejiang, China: Zhejiang University, 2004.

[9] K. Tian. "Research on credit risk of commercial banks' personal housing mortgage loans based on the empirical study of logistic model". Science and Technology Information (academic), 2008, vol. 27, pp. 418-420.

[10] D. Rosch. "An empirical comparison of default risk forecasts from alternative credit rating philosophies". International Journal of Forecasting, 2005, vol. 21, pp. 37-51.

[11] A. Ben-Tal, L. E. Ghaoui, A. Nemirovski. Robust Optimization. Princeton, US: Princeton University Press, 2009.

[12] S. I. Gass, C. M. Harris. Encyclopedia of Operations Research and Management Science. US: Springer, 2001, pp. 790-790.

[13] R. C. Merton. "On the pricing of corporate debt: the risk structure of interest rates". Journal of Finance, 1974, vol. 5, pp. $449-470$.

[14] F. Black, M. Scholes. "The Pricing of Options and Corporate Liabilities". Journal of Political Economy, 1973, vol. 81(3), pp. 637-654.

[15] G. Cornuejols, R. Tutuncu. Optimization method in finance. Pittsburgh: Carnegie Mellon University, 2006.

[16] X. K. DU. "Research on prepayment behavior in China residential mortgage-backed securitization". Hefei, China: University of Science and Technology of China, 2010. 